Acta Cryst. (1997). A53, 1-6

\title{
International Union of Crystallography
}

\section{Acta Crystallographica Section A Notes for Authors}

\section{Scientific scope of Section A}

Section A of Acta Crystallographica publishes papers reporting fundamental advances in all areas of crystallography in the broadest sense. The central themes are, on the one hand, experimental and theoretical studies of the properties and arrangements of atoms, ions and molecules in condensed matter, ideal or real, and of their symmetry and, on the other, the theoretical and experimental aspects of the various methods to determine these arrangements. In contrast, Section $B$ deals with papers in which the structure of a compound or a family of compounds is the primary focus of the research described while Section $D$ is devoted to molecules of biological interest. A more complete definition of scientific scope is given in an Editorial [Acta Cryst. (1994), A50, 1].

\section{Categories of contributions}

\subsection{Research Papers}

Full-length Research Papers should not normally exceed 15 journal pages (about 15000 words or 60 double-spaced manuscript pages). They should be submitted to one of the Co-editors or to the Section Editor, taking into account their advertised areas of expertise (first) and their geographical proximity (second). Research Papers in French, German or Russian must be sent to a Co-editor in the appropriate country.

\subsection{Short Communications}

Short Communications are intended for the presentation of topics of limited scope, or for preliminary announcements of novel research findings. They are not intended for interim reports of work in progress, and must report results that are of scientific value in their own right.

Short Communications must not exceed two journal pages (about 1500 words or six double-spaced manuscript pages). A maximum of two figures and two tables of appropriate size are permitted.

All Short Communications should be submitted to the Section Editor.

\subsection{Lead Articles}

Lead Articles are authoritative, comprehensive and forwardlooking reviews of major areas of research interest. They are always commissioned by the Section Editor, on the advice of the Editorial Board. Suggestions for suitable topics and of potential author(s) are welcomed by the Section Editor for discussion with the Board.

The Editor will discuss the treatment of the topic, the length of the Article and the delivery date of the manuscript with invited author(s); completed manuscripts will be refereed in the normal manner. Lead Articles will be highlighted on the cover of the relevant issue, clearly identified within the journal and will carry brief biographical details of their author(s), which should be provided by the author(s) on submission of the article.

\subsection{Topical Reviews}

A Topical Review is a short, highly focused survey covering a relatively narrow area of current research interest. It should be written so as to benefit both subject experts and also a more general audience of interested research scientists. A Topical Review should not aim to be comprehensive, but a brief introduction should provide historical perspective and a brief conclusion should indicate likely future directions. It is hoped that a less formal style of scientific writing can prevail in these articles.

Topical Reviews will be limited to about ten journal pages (10000 words or 40 double-spaced manuscript pages) except in special agreed circumstances. They will be commissioned by the Section Editor either personally, or following a formal proposal by prospective author(s). A letter of intent should be sent (faxed or e-mailed), giving the proposed topic, its importance and an indication of the material to be covered. This letter may be sent to one or more members of the Editorial Board for comment before the full article is commissioned. Once commissioned, author(s) will have priority in their topic within an agreed submission deadline. Topical Reviews will be refereed in the normal way, be highlighted within the journal issue, and carry brief biographical details of their author(s), which should be provided by the author(s) on submission of the article. It is hoped that direct contributions by prospective author(s) will become the norm for Topical Reviews.

\subsection{Letters to the Editor}

These may deal with non-technical aspects of crystallography, its role, its propagation, the proper function of its Societies etc., or may make a technical observation that would usefully be brought to a wider audience. Letters should be sent to the Section Editor or to the Editor-in-Chief of Acta Crystallographica only. They will not be formally refereed.

\section{Submission and handling of manuscripts}

\subsection{Submission}

Manuscripts should be prepared on one side of the paper in double-spaced format. All contributions should be submitted in triplicate and authors are reminded to keep an exact copy of the submission for later editorial adjustments and for checking proofs. A machine-readable version of the final accepted manuscript will be requested by the editorial office, provided it can be prepared using one of the four word-processing formats listed in $\S 3.4$. This request is designed to reduce publication times.

Every issue of the journal contains the names and addresses of the Section Editor, the Co-editors of Acta Crystallographica Section $A$ and of the Managing Editor. Contributions should be submitted as follows:

Research Papers: to any of the Co-editors or the Section Editor, having regard firstly to their areas of expertise and secondly to their geographical location. Papers in French, German or Russian must be sent to a Co-editor in the appropriate country.

Short Communications: to the Section Editor

Lead Articles and Topical Reviews: these will be handled by the Section Editor as described in $\$ 2$ of these Notes. 


\subsection{Languages of publication}

Acta Crystallographica Section A will publish papers in English, French, German and Russian. All contributions must be accompanied by an English language Abstract and synopsis.

\subsection{Handling of manuscripts}

All contributions will be seen by referees (normally two) before they can be accepted for publication. The editor to whom the manuscript is sent is responsible for choosing referees and for accepting or rejecting the paper. This responsibility includes decisions on the final form of the paper and interpretation of these Notes when necessary.

If changes to a manuscript requested by the editorial staff or the Co-editor are not received within three months of transmittal to the author, the submission will automatically be withdrawn. Any subsequent communication of the material will be treated as a new submission in the editorial process.

For accepted papers, it is the responsibility of the Managing Editor to prepare the paper for printing. This may involve correspondence with the authors and/or the responsible editor in order to resolve ambiguities or to obtain satisfactory figures or tables. The date of acceptance that will appear on the published paper is the date on which the Managing Editor receives the last item required. Proofs will be sent to the author who signed the letter of submission unless the Managing Editor is informed of some other suitable arrangement.

On rare occasions an editor may consider that a paper is better suited to a section of Acta Crystallographica other than that specified by the author(s), to the Journal of Applied Crystallography or to the Journal of Synchrotron Radiation. Alterations to the section or journal of publication will only be made after full discussion with the communicating author.

\subsection{File formats}

A machine-readable version of the paper should be prepared in $\mathrm{T}_{\mathrm{E}} \mathrm{X}, \mathrm{LAT}_{\mathrm{E}} \mathrm{X}$, WordPerfect or Word. Authors writing their papers in Word or WordPerfect are encouraged to use the template available from the editorial office by e-mail (med@iucr.ac.uk) or by ftp (from the 'template' directory). After acceptance of the paper for publication, authors should send the version of the paper accepted by the Co-editor to the editorial office by e-mail or $\mathrm{ftp}(\mathrm{see} \S 12)$ or on diskette.

\subsection{Author's warranty}

The submission of a paper is taken as an implicit guarantee that the work is original, that it is the author(s) own work, that all authors concur with and are aware of the submission, that all workers involved in the study are listed as authors or given proper credit in the acknowledgements, that the manuscript has not already been published (in any language or medium), and that it is not being considered and will not be offered elsewhere while under consideration for an IUCr journal. For these reasons, the submission must be made over the signature of at least one author.

\subsection{Copyright}

Except as required otherwise by national laws, an author must sign and submit a copy of the Transfer of Copyright Agreement form (given at the end of these Notes) for each manuscript before it can be accepted.

\subsection{Author grievance procedure}

An author who believes that a paper has been unjustifiably treated by the Co-editor may appeal initially to the Section Editor and then to the Editor-in-Chief if still aggrieved by the decision.

\subsection{Contact e-mail address}

The contact author should, where possible, provide an e-mail address. This will be used for editorial communications and will normally appear in the published paper.

\section{Layout and typography}

Contributions should be prepared on one side of the paper in double-spaced format with wide margins, and should conform to the general editorial style of the journal.

\subsection{Type style}

The editorial staff in Chester will indicate to the printer the style of type to be used. It is better that authors should not indicate type style at all rather than do so in a way different from that used by the printers. However, it is helpful if authors indicate vectors and tensors by a wavy underline.

\subsection{Mathematics and letter symbols}

The use of the stop (period) to denote multiplication should be avoided except in scalar products. Generally no sign is required but, when one is, a multiplication sign $(x)$ should be used.

Greek letters should not be spelled out except in marginal notes of clarification.

Care should be taken not to cause confusion by using the same letter symbol in two different meanings.

Gothic, script or other unusual lettering should be identified in marginal notes. The printer may be instructed to use another type face if that indicated by the author is not readily available.

Equations, including those in published Appendices, should be numbered in a single series.

\section{Abstract and synopsis}

All contributions must be accompanied by an English language Abstract and a one or two sentence synopsis of the main findings of the paper for inclusion in the Table of Contents for the relevant issue. The Abstract should state as specifically and as quantitatively as possible the principal results obtained.

The Abstract should be suitable for reproduction by abstracting services without change in wording. It should not repeat information given in the title. Ordinarily 200 words suffice for Research Papers, Lead Articles and Topical Reviews and 100 words for Short Communications. It should make no reference to tables, diagrams, atom numbers or formulae contained in the paper. It should not contain footnotes. Numerical information given in the Abstract should not be repeated in the text. It should not include the use of 'we' or 'I'.

Literature references in an Abstract are discouraged. If a reference is unavoidable, it should be sufficiently full within the Abstract for unambiguous identification, e.g. [Abrahams (1994). Acta Cryst. A50, 658-685].

\section{Diagrams and photographs ('figures')}

\subsection{Design}

The choice of tables and figures should be optimized to produce the shortest printed paper consistent with clarity. Duplicate presentation of the same information in both tables and figures is to be avoided, as is redundancy with the text.

In structural papers it is preferred that (i) distances and angles be given in tabular form and (ii) that a chemical structural diagram be included for organic and metal-organic compounds. 
Supplementary diagrams may be deposited (see $\$ 11.1$ ).

In a charge-density paper only those figures which are strictly necessary to illustrate the techniques or results described will be published: any others will be deposited. The text should be adequate to give the remaining information.

In papers which use powder profile fitting or refinement (Rietveld) methods, figures which present the experimental and calculated diffraction profiles of the material studied should also contain the difference profile. As primary diffraction data cannot be satisfactorily extracted from such figures, the basic digital diffraction data should be deposited (see \$11.4).

\subsection{Quality}

Diagrams must be provided in 'hard-copy' form, that is, as careful drawings in black ink or as high-quality photographic copies (glazed prints, not mounted). An individual hard-copy diagram must be provided for each figure.

\subsection{Colour figures}

Figures in colour are accepted at no cost to the author provided that the editor agrees that they improve the understanding of the paper. They should be provided as glossy prints or slides; laser printer or photocopier output will generally be unsatisfactory for colour reproduction. Slides should be accompanied by a photocopy showing the required figure layout.

\subsection{Size}

Diagrams should be as small as possible consistent with legibility. If possible, each diagram should be provided on a separate sheet of about A4 International Paper Size $(210 \times 297 \mathrm{~mm})$. They will normally be further reduced by the printer, generally so that the greatest width including lettering is less than the width of a column of the journal (approximately $80 \mathrm{~mm}$ ). Figures at greater than column width are allowed at editorial discretion.

\subsection{Stereofigures}

Stereofigures are welcomed in Section A. Atom labelling when included should be on both left and right views in stereo perspective.

\subsection{Lettering and symbols}

Fine-scale details and lettering must be large enough to be clearly legible (not less than $1.2 \mathrm{~mm}$ in height) after the whole diagram has been reduced to one column $(80 \mathrm{~mm})$ width

Lettering should be kept to a minimum; distances, bond angles and torsion angles should be given as tables and descriptive matter should be placed in the legend.

\subsection{Numbering and legends}

Diagrams and photographs are to be numbered as figures in a single series, normally in the order in which they are referred to in the text. A list of the legends ('figure captions') is to be attached to the manuscript.

\subsection{Electronic submission of figures}

After acceptance of the paper for publication, authors may send figures direct to the editorial office by e-mail or ftp (see $\S 12)$.

Figures may be sent as HPGL, PostScript or encapsulated PostScript files. A complete list of file formats that are supported can be obtained from the editorial office. Hard-copy figures must be provided in all cases.

\section{Tables}

\subsection{Economy in use of tables}

Numerical information is generally most economically presented in tables. Text and diagrams should not be redundant with the tables.

Small tables will normally be set in type while large tables may be photographically reproduced or deposited.

Structure factors, anisotropic displacement parameters, leastsquares planes and unrefined $\mathrm{H}$-atom coordinates are deposited, except when the nature of the paper requires that they be immediately available.

\subsection{Design, numbering and size}

Tables must be numbered in a single series of arabic numerals, normally in the order in which they are referred to in the text. They should be provided with a caption either at the top or, if the table is to be photographed, on a separate sheet.

Tables should be carefully designed to occupy a minimum of space consistent with clarity. Tables to be photographed should be prepared in single spacing, without excessive space between columns.

\section{Nomenclature}

\subsection{Crystallographic nomenclature}

Atoms of the same chemical species within an asymmetric unit should be distinguished by an appended arabic numeral. Chemical and crystallographic numbering should be in agreement wherever possible. When it is necessary to distinguish crystallographically equivalent atoms in different asymmetric units the distinction should be made by lower-case roman numeral superscripts (i.e. i, ii, iii etc.) to the original atom labels.

Authors are encouraged to follow the recommendation of the International Organization for Standardization (ISO) and use the term standard uncertainty, abbreviated s.u., in place of the traditional term estimated standard deviation [see Schwarzenbach, Abrahams, Flack, Prince \& Wilson (1995). Acta Cryst. A51, 565-569]. The standard uncertainty should be expressed as a number in parentheses following the numerical result and should be on the scale of the least significant digits of the result.

Space groups should be designated by the Hermann-Mauguin symbols. Standard cell settings, as listed in Volume A of International Tables for Crystallography, should be used unless objective reasons to the contrary are stated. When a non-standard setting is used, the list of equivalent positions should be given. Hermann-Mauguin symbols should also be used for designating point groups and molecular symmetry. It is helpful if the origin used is stated explicitly where there is a choice.

The choice of axes should normally follow the recommendations of the Commission on Crystallographic Data [Kennard, Speakman \& Donnay (1967). Acta Cryst. 22, 445-449].

A symbol such as 123 or $h k l$ without brackets is understood to be a reflection, (123) or $(h k l)$ a plane or set of planes, [123] or $[u v w]$ a direction, $\{h k l\}$ a form and $\langle u v w\rangle$ all crystallographically equivalent directions of the type $[u v w]$. Other bracket notations should be explicitly defined.

For the nomenclature of crystal families, Bravais-lattice types and arithmetic classes see de Wolff et al. [Acta Cryst. (1985), A41, 278-280].

For the nomenclature of polytypes see Guinier et al. [Acta Cryst. (1984), A40, 399-404].

For the nomenclature of inorganic structure types see Limade-Faria et al. [Acta Cryst. (1990), A46, 1-11]. 
For symbols for symmetry elements and symmetry operations see de Wolff et al. [Acta Cryst. (1992), A48, 727-732].

Anisotropic displacement parameters should be reported as $U$ values with the indices $i j$ given as superscripts [see Trueblood $e t$ al. (1996). Acta Cryst. A52, 770-781].

\subsection{Nomenclature of chemical compounds etc.}

Names of chemical compounds and minerals are not always unambiguous. Authors should therefore quote the chemical formulae, including chemical structural diagrams for organic and metal-organic compounds, of the substances dealt with in their papers.

Chemical formulae and nomenclature should conform to the rules of nomenclature established by the International Union of Pure and Applied Chemistry (IUPAC), the International Union of Biochemistry and Molecular Biology (IUBMB), the International Mineralogical Association and other appropriate bodies. As far as possible the crystallographic nomenclature should correspond to the systematic name.

Any accepted trivial or nonsystematic name may be retained, but the corresponding systematic (IUPAC) name should also be given.

If help on assigning systematic names is sought from advisory sources, authors are requested to indicate the source consulted.

\subsection{Units}

The International System of Units (SI) is used except that the ångström (symbol $\AA$, defined as $10^{-10} \mathrm{~m}$ ) is generally preferred to the nanometre $(\mathrm{nm})$ or picometre $(\mathrm{pm})$ as the appropriate unit of length. Recommended prefixes of decimal multiples should be used rather than ' $\times 10^{n}$ '.

\section{References}

References to published work must be indicated by giving the authors' names followed immediately by the year of publication, e.g. Neder, Frey \& Schulz (1990) or (Neder, Frey \& Schulz, 1990). Where there are six or more authors the reference in the text should be indicated in the form Smith et al. (1989) or (Smith et al., 1989) etc. (all authors should be included in the full list)

At the end of the paper a list giving full details of all references should be appended separately. In the reference list, entries for journals [abbreviated in the style of Chemical Abstracts (the abbreviations Acta Cryst., J. Appl. Cryst. and J. Synchrotron Rad. are exceptions)], books, multi-author books, computer programs, personal communications and undated documents should be arranged alphabetically and conform with the following style:

Cowley, J. M. (1993). Editor. Electron Diffraction Techniques. Oxford University Press.

Cowley, J. M. \& Moodie, A. F. (1992). P. P. Ewald and his Dynamical Theory of Diffraction, edited by D. W. J. Cruickshank, H. J. Juretschke \& N. Kato, ch. 10. IUCr/Oxford University Press.

CRC Handbook of Chemistry and Physics (1983). 64th ed., edited by R. C. Weast, p. D-46. Boca Raton, Florida: CRC Press.

Dmitrienko, V. E. (1990). J. Phys. (Paris), 51, 2712-2732.

Maslen, E. N., Fox, A. G. \& O'Keefe, M. A. (1992). International Tables for Crystallography, Vol. C, edited by A. J. C. Wilson, Section 6.1.1. Dordrecht: Kluwer Academic Publishers.

Perkins, P. (undated). $\mathrm{PhD}$ thesis, University of London, England.
Petříček, V. \& Coppens, P. (1988). Acta Cryst. A44, 235-239.

Petř́ícek, V., Coppens, P. \& Becker, P. (1985). Acta Cryst. A41, 478-483.

Sheldrick, G. M. (1976). SHELX76. Program for Crystal Structure Determination. University of Cambridge, England.

Smith, J. M. (1994). Personal communication.

Shmueli, U. \& Weiss, G. H. (1985a). Acta Cryst. A41, 401-408.

Shmueli, U. \& Weiss, G. H. (1985b). Structure and Statistics in Crystallography, edited by A. J. C. Wilson, pp. 53-66. Guilderland: Academic Press.

Tanaka, M. \& Tsuda, K. (1991). Proceedings of the 26th Meeting of the Microbeam Analysis Society, San Jose, USA, pp. 145-146.

Woolfson, M. M. (1961). Direct Methods in Crystallography. Oxford: Clarendon Press.

Zhou, P. F. (1993). PhD thesis, McMaster University, Hamilton, Ontario, Canada.

Note that inclusive page numbers must be given.

When more than ten references are taken from a data base (usually for a structural paper), a condensed reference notation of the Coden type should be used.

\section{Crystal structure determinations}

Papers which report the results of crystal structure determinations of small molecules must report the associated numerical data as required in Notes for Authors for Section C of Acta Crystallographica. These data should be supplied in a machinereadable file in CIF format. All numerical data will be checked in Chester for internal consistency.

\section{Supplementary publication procedure (deposition)}

\subsection{Purpose and scope}

Parts of some papers are of interest to only a small number of readers and the cost of printing these parts is not warranted. Arrangements have therefore been made for such material to be deposited with the $\mathrm{IUCr}$, with the Protein Data Bank at Brookhaven and with the ICDD as appropriate

The information to be deposited is at the discretion of the editor and may include:

Details of the experimental procedure.

Details of the stages of structure refinement.

Details of mathematical derivations given only in outline in the main text and in mathematical Appendices.

Lengthy discussion of points that are not of general interest or that do not lead to definite conclusions but that do have significant value.

Additional diagrams.

For papers reporting results of crystal structure determinations the following additional items are required:

Structure factors; weak reflections classified as unobserved should be included.

Anisotropic displacement parameters, including e.s.d.'s.

Least-squares planes and deviations from them.

Calculated $\mathrm{H}$-atom coordinates. 
Normal intermolecular distances.

Tables of non-essential bond lengths and angles (e.g. distances and angles in peripheral phenyl rings) or those of limited accuracy (e.g. those involving $\mathrm{H}$ atoms whose parameters have not been refined).

All material to be deposited should be clearly so marked; it will be subject to the usual refereeing procedure.

\subsection{Preparation of material for deposit}

Material for deposit should:

be of a quality such that photocopies of it are completely legible;

have dimensions for text and tables not exceeding A4 International Paper Size $(210 \times 297 \mathrm{~mm})$ (larger dimensions may be acceptable in exceptional circumstances);

not be photographically reduced so that character heights are less than $1.2 \mathrm{~mm}$;

contain the title page of the paper to which it relates (including the Abstract);

have pages clearly numbered to ensure the correct sequence;

be sent in triplicate with the paper when it is submitted (but note that only one copy of the structure factors is required).

After acceptance of the paper for publication, material for deposition may be sent direct to the editorial office by e-mail or ftp (see $\$ 12)$.

\subsection{Macromolecular structures}

Data deposited should correspond to the level of detail described in the structural paper. For all structural studies of macromolecules, coordinates and structure factors must be deposited with the Protein Data Bank at Brookhaven National Laboratory if a total molecular structure has been reported. Authors should supply the Protein Data Bank reference codes for inclusion in the published paper.

An author may request that the structure factors be given a privileged status for a period of no longer than four years and for atomic coordinates no longer than one year from the date of publication. Earlier release would require the specific consent of the author.

\subsection{Powder diffraction data}

For papers that present the results of powder diffraction profile fitting or refinement (Rietveld) methods, the primary diffraction data, i.e. the numerical intensity of each measured point on the profile as a function of scattering angle, will be deposited.

Co-editors will send powder diffraction data (reported either in the paper or in the deposited material) to the International Centre for Diffraction Data (ICDD), 12 Campus Boulevard, Newtown Square, PA 19073-3273, USA. These data will then be checked and assigned an ICDD reference number which will, where possible, be published in the paper.

\section{File transfer}

After acceptance of the paper for publication, authors with computer access to the Internet may use anonymous file transfer protocol (ftp) to transfer large electronic files to the editorial office in Chester. Files larger than $70 \mathrm{~K}$ bytes should be transferred in this way, smaller files can be sent by e-mail to med@iucr.ac.uk.

The procedure for transferring files by ftp is described below. Files need to be deposited in a directory called 'incoming/a' with a filename constructed from the reference number supplied by the Co-editor. Files containing text in $\mathrm{T}_{\mathrm{E} X}$ or $\mathrm{LAT}_{\mathrm{E}} \mathrm{X}$ should be given the extension .tex, and WordPerfect or Word files should be given the extensions .wp or .doc, respectively. Files containing diagrams in HPGL, PostScript or encapsulated PostScript format should be given the extensions .hpg, .ps or .eps, respectively. Multiple files for the same submission should be identified by filenames constructed as ref.id.ext where id indicates the contents, e.g. xz1087. fig1.ps and xz1087.fig2.ps.

The procedure for transferring files is given below.

(i) On your workstation enter:

ftp ftp.iucr.ac.uk

(ii) Wait for Name ...: prompt and enter: anonymous

(iii) Wait for Password: prompt and enter: your e-mail address

(iv) Wait for $f t p>$ prompt and enter: cd incoming/a

(v) Transfer a file from your account

(e.g. j29.ps) as an identifiable name

(e.g. ja0325.ps):

put j29.ps ja0325.ps

(vi) Wait for $f t p>$ prompt before sending another file

(vii) Finish off the ftp session by entering:

bye

(viii) Send an e-mail to Chester (medeiucr.ac.uk) with a list of the files transferred by ftp

\section{Electronic status information}

Authors may obtain information about the current status of their papers via the world-wide web at the address http://www.iucr.ac.uk/docs/status.html/ (authors will need to provide the Co-editor reference number of their paper and the last name of one of the authors) or by e-mail by sending an e-mail message to status@iucr.ac.uk with the Co-editor reference number and the name of one of the authors as the subject line (e.g. JA0325 Smith). The body of the message should be empty. A status report will be returned by e-mail.

\section{Reprints}

Twenty-five reprints of each published article will be provided to a nominated author free of charge. 


\section{International Union of Crystallography \\ Transfer of Copyright Agreement}

Title of Article (Please type or use capital letters)

Authors (Please type or use capital letters)

Copyright to the above article is hereby transferred (except as otherwise required by national laws*) to the International Union of Crystallography, effective if and when the article is accepted for publication in Acta Crystallographica, Journal of Applied Crystallography or Journal of Synchrotron Radiation. In addition to reproduction in conventional printed form your article will be stored electronically. Your assignment of Copyright signifies your agreement to the journal making arrangements to include your paper in document delivery services, CD-ROMs and electronic databases, etc., worldwide. This transfer of copyright also applies to data submitted in machine-readable form. However, the authors reserve the following:

(1) All proprietary rights other than copyright, such as patent rights.

(2) The right to use all or part of this article in future works prepared by or on the behalf of the author.

(3) In the case of 'work for hire', the right of the employer to incorporate all or part of this article in future works.

(4) The royalty-free right of the employer to make copies of this article, without further permission, for his or her own use but not for resale. Any identification or notice appearing on the pages to be reproduced must not be deleted.

Signature

Name and position, if not author

Date

\section{Signature}

Name and position, if not author

This Transfer of Copyright Agreement must be signed by at least one of the authors (who agrees to inform the others, if any) or, in the case of a 'work made for hire', by the employer.

By signing this form you certify that your contribution is your original work, has not been published before (in any language or medium) and is not being considered for publication elsewhere; that you have obtained permission for and acknowledged the source of any excerpts from other copyright works; and that to the best of your knowledge your paper contains no statements which are libellous, unlawful or in any way actionable.

The signed statement must be received before the article can be accepted for publication. Requests for further information should be sent to the Executive Secretary of the Union.

\footnotetext{
* In this case please give further details overleaf.
}

For use of the International Union of Crystallography only.

\begin{tabular}{|c|c|c|c|}
\hline M. E. Ref. & Co-editor Ref. & Issue & Journal \\
\hline
\end{tabular}

This form may be photocopied. 